\title{
Multi products single machine EPQ model with immediate rework process
}

\author{
Ata Allah Taleizadeh ${ }^{\mathrm{a}}$ Leopoldo Eduardo Cárdenas-Barrón ${ }^{\mathbf{b}}$, Jahangir Biabani ${ }^{\mathrm{c}}$ and Ramin \\ Nikousokhan ${ }^{\mathrm{d}}$
}

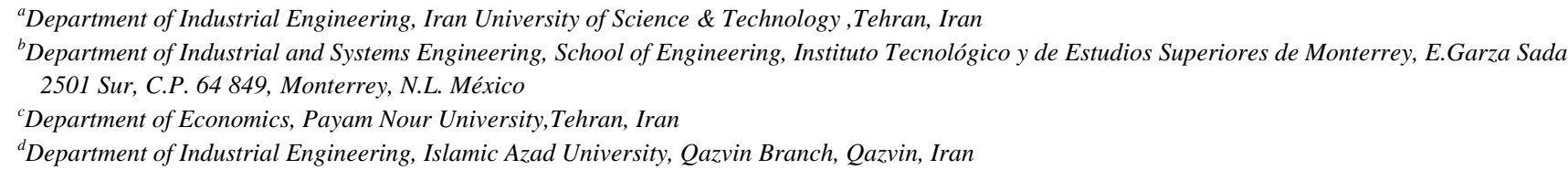

\begin{tabular}{l}
\hline A R T I C L E I N F O \\
\hline Article history: \\
Received 20 August 2011 \\
Received in revised form \\
August, 31, 2011 \\
Accepted August, 312011 \\
Available online \\
1 September 2011 \\
\hline Keywords: \\
Economic production quantity \\
Rework process \\
Limited production capacity
\end{tabular}
\begin{abstract}
A B S T R A C T
This paper develops an economic production quantity (EPQ) inventory model with rework process for a single stage production system with one machine. The existence of a unique machine results in limited production capacity. The aim of this research is to determine both the optimal cycle length and the optimal production quantity for each product to minimize the expected total cost (holding, production, setup, rework costs). The convexity of the inventory model is derived. Also the objective function is proved to be convex. The proposed inventory model is validated with illustrating numerical examples and the optimal period length and the total system cost are analyzed.
\end{abstract}

\section{Introduction}

Raw material is considered as one of the main issues for any manufacturing process. The management of material begins by the regulation of the flow of the raw materials which enters to organization till they are changed into final products. An efficient strategy on raw materials could lead to higher revenue growth and profitability. During the past few decades, there have been tremendous efforts to adapt globalization by obtaining resources from different regions of the world. Therefore, we may expect to use several resources to source and distribute both raw materials and finished goods. In this direction, the key success is to maintain a high level of customer satisfaction. In other word, any disruption in service delivery may lead to lose market share. As a result, inventory management, production planning and scheduling play an important role especially for world class manufacturers.

In manufacturing companies, when products are internally manufactured instead of being obtained from an outside vendor, the economic production quantity (EPQ) inventory model is frequently employed to calculate the optimal lot size minimizing the overall production/inventory costs. One

* Corresponding author Tel.: +52 8183284235 Fax: +52 8183284153

E-mail: lecarden@itesm.mx (L. E. Cárdenas-Barrón) 
primary assumption with any EPQ inventory model is that the products are manufactured perfectly and there is no need of a rework process. However, due to process deterioration, one may end up having imperfect quality items. Therefore, we may attempt to reduce the total production/inventory expenditures by repairing the defective items. There are good examples of the rework processes for example: printed circuit board assembly in the PCBA manufacturing, metal components, and plastic injection molding, just to name a few. Cheng (1991) develops an order quantity inventory model for imperfect production processes when production cost is a function of demand. Chiu et al. (2003) propose a economic production quantity inventory model when scrap items are taken into consideration. Chung (1997) determines some bounds for production lot sizing with machine breakdown.

The economic production cycles with imperfect production processes are studied by Rosenblatt and Lee (1986) and Lee and Rosenblatt (1987); where a manufacturing process can shift from a normal condition to an out-of-control condition. Hayek and Salameh (2001) propose an optimal operating policy for the finite production model with reworking and imperfect quality items. In their inventory model, any defective item could be repaired and backorders are permitted. Rework and breakdown are considered significantly in variety forms (Chiu (2003), Chiu (2007) and Chiu et al. (2007)). Jamal et al. (2004) present a new method when production lot-sizing were faced with imperfect maintenance. Cárdenas-Barrón (2007) corrects the solutions to examples in Jamal et al. (2004) and Cárdenas-Barrón (2008) derives in a simple way the Jamal et al. (2004)'s two inventory policies. The EPQ with rework process and planned backorders can be found in Cárdenas-Barrón (2009a). The multi-stage production system with rework consideration is dealt in Sarker et al. (2008) and Cárdenas-Barrón (2009b).

Chan et al. (2003) study the traditional EPQ with an integrated model with rework and reject items. Chiu and Chiu (2003) study optimal replenishment policy for an imperfect quality EPQ inventory model with backlogging and failure. They derive the optimal lot size using the classical optimization approach based on differential calculus. Islam and Roy (2006) formulate a fuzzy form of EPQ model by considering flexible and reliable production process. Bayindir et al. (2007) develop a new EPQ model with general inventory cost rate function and piecewise linear concave production costs. Hou (2007) investigate an EPQ model with setup cost and process quality as a function of capital expenditure. Then, he develops an efficient procedure to obtain the optimal production run time, setup cost, and process quality. Chiu et al. (2007) study an EPQ inventory model with scrap, rework, and stochastic machine breakdowns. Their inventory model determines both the optimal run time and production lot size. In a subsequent paper, Chiu (2008) develops an optimal solution for the same problem where no information of the derivates was needed. Li et al. (2008) study an EPQ inventory model with planned backorders to evaluate the impact of the postponement strategy on a manufacturer in a supply chain.

Pentico et al. (2009) extend the EPQ inventory model with partial backordering when production lot size and period length are also considered. Teng and Chung (2009) develop another EPQ inventory model under two levels of trade credit policy to optimize the production quantity and period length. Chiu et al. (2004) consider the effects of random defective rate and imperfect rework process on EPQ inventory model. Wee et al. (2007) present an inventory model for items with imperfect quality and shortage backordering. Taleizadeh et al. (2010a) present economic production quantity model with scrapped items and limited production capacity. At the same time, Taleizadeh et al. (2010b) introduce multi-product single-machine production system with stochastic scrapped production rate, partial backordering and service level constraint. Taleizadeh et al. (2010c) also develop a multi product single machine EPQ model with failure and rework when partial backordering exists. In two subsequent research works, Taleizadeh et al. (2011a) extend a multi product single machine EPQ inventory model with multiple batch sizes and Taleizadeh et al. (2011b) develop an extended a multi product single machine EPQ inventory model. 
This paper is organized as follows. Section 2 develops the EPQ inventory model with rework process for a single stage production system with one machine. Section 3 presents the solution procedure to solve the optimization problem. Section 4 solves numerical examples and presents a sensitivity analysis. Finally, some conclusions and future researches are given in Section 5.

\section{Modeling and formulation}

The EPQ inventory model with two kinds of rework processes was considered by Jamal et al. (2004). Their models determine the optimum batch quantity in a single-stage system in which the rework is performed under two different operational policies to minimize the total system cost. An inventory model for a single-stage production system with fraction defective and rework process facility involves various types of cost functions such as setup cost, processing cost, inventory carrying cost, in-process inventory carrying cost for reworking, and penalty cost for defective items. In this paper, we develop the model of Jamal et al. (2004) by considering multi products single machine system with capacity limitation. In fact the existence of a unique machine results in limited production capacity. In this research, we assume demands of each product are constant over the production planning period.

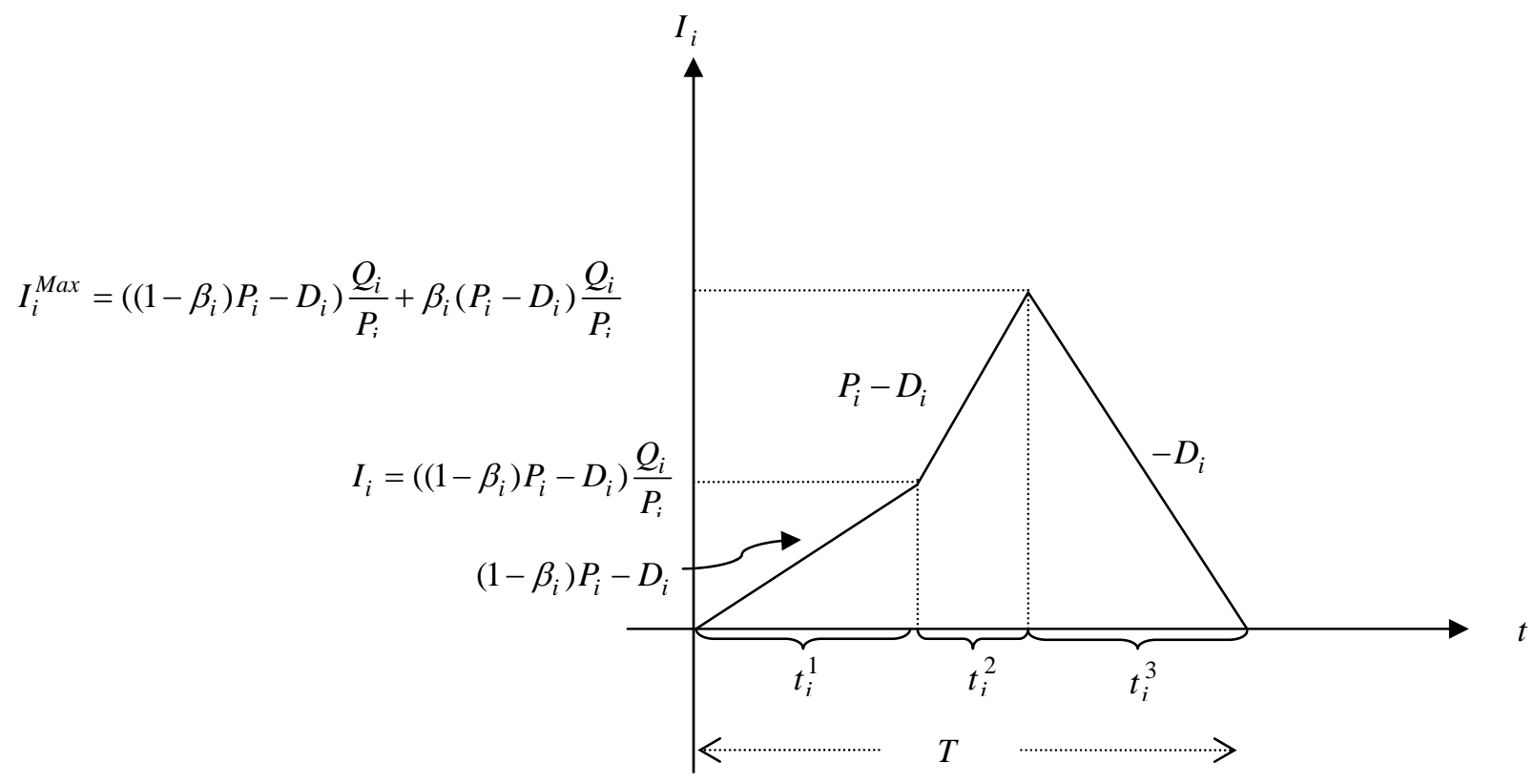

Fig. 1. On hand inventory of perfect quality items

Proportion of defective of each product is constant in each cycle and production rate of non-defective items is constant and is greater than the demand rate of each product. Scrap is not produced at any cycle and no defectives are produced during the rework process. Production and rework are accomplished using the same resource at the same speed and shortage is not allowed. A real constant production capacity limitation on a single machine in which all products are produced and that the setup cost is considered nonzero. Since all products are manufactured and reworked on a single machine with a limited capacity, the cycle length for all of them is equal $\left(T_{1}=T_{2}=\cdots=T_{n}=T\right)$. Since the problem at hand is of multiproduct with products $i=1,2, \cdots, n$, the following notations are used:

$Q_{i}$ : Production lot size of $i^{\text {th }}$ product for each cycle (Decision variables);

$T$ : Cycle length (Decision variable);

$P_{i}$ : Production rate of $i^{\text {th }}$ product for each cycle; 
$D_{i}$ : Demand rate of $i^{\text {th }}$ product;

$\beta_{i}$ : Proportion of defective s of $i^{\text {th }}$ product in each cycle;

$A_{i}$ : Setup cost for each production run of $i^{\text {th }}$ product;

$S_{i}$ : Setup time of machine to produce the $i^{\text {th }}$ product;

$N$ : Number of cycles per year;

$T C$ : Total inventory costs per year;

$I_{i}$ : Maximum level of on-hand inventory of $i^{\text {th }}$ product when regular production process stops;

$I_{i}^{\text {Max }}$ : Maximum level of on-hand inventory of $i^{\text {th }}$ product in units, when the reworking ends;

$C_{i}^{P}$ : Production cost of $i^{\text {th }}$ product, \$/item;

$C_{i}^{h}$ :Holding cost of $i^{\text {th }}$ product per item per unit time, \$/item/unit time.

\subsection{Formulation}

Initially the problem is modeled as a single product case and then it is modified as a multi product case. The basic assumption of EPQ model with rework process produced is that $P_{i}$ must always be greater than or equal to the sum of demand rate $D_{i}$. Therefore we have:

$\left(\left(1-\beta_{i}\right) P_{i}-D_{i}\right) \geq 0$.

The production cycle length (see Fig. 1) is the summation of the production uptime, the reworking time and the production downtime:

$T=\sum_{j=1}^{3} t_{i}^{j}$

where the production uptime (including healthy and defective items) is $t_{i}^{1}$, the reworking time is $t_{i}^{2}$ and the production downtime is $t_{i}^{3}$. To model the problem, a part of the modeling procedure is adopted from Jamal et al. (2004). Since all products are manufactured on a single machine with a limited capacity, the cycle length for all of them are equal $\left(T_{1}=T_{2}=\cdots=T_{n}=T\right)$. Then, based on Fig. 1 , for $i=1,2, \cdots, n$, we have:

$t_{i}^{1}=\frac{Q_{i}}{P_{i}}$,

$t_{i}^{2}=\beta_{i} \frac{Q_{i}}{P_{i}}$,

$t_{i}^{3}=\frac{\left(1-\frac{D_{i}}{P_{i}}-\beta_{i} \frac{D_{i}}{P_{i}}\right) Q_{i}}{D_{i}}$.

It is evident from Fig. 1 that:

$I_{i}=\left(\left(1-\beta_{i}\right) P_{i}-D_{i}\right) \frac{Q_{i}}{P_{i}}$,

$I_{i}^{\text {Max }}=I_{i}+\beta_{i}\left(P_{i}-D_{i}\right) \frac{Q_{i}}{P_{i}}=\left(\left(1-\beta_{i}\right) P_{i}-D_{i}\right) \frac{Q_{i}}{P_{i}}+\beta_{i}\left(P_{i}-D_{i}\right) \frac{Q_{i}}{P_{i}}$. 
Hence, according to Eq. (2) the cycle length for a single product state is:

$T=\sum_{j=1}^{3} t_{i}^{j}=\frac{Q_{i}}{D_{i}}$

or,

$Q_{i}=D_{i} T$.

The total production cost of the system consists of setup cost, processing cost, rework cost and inventory carrying costs. Defective items are produced in every batch and they are reworked within the same cycle. During the rework of defective items, again some processing costs and inventory holding costs are incurred for processing and holding the reworked quantities as well. The total inventory cost per year $T C$ is:

$T C=\overbrace{N C_{i}^{P} Q_{i}}^{\text {Production Cost }}+\overbrace{N A_{i}}^{\text {Setup Cost }}+\overbrace{N C_{i}^{P} \beta_{i} Q_{i}}^{\text {Rework Cost }}+\overbrace{N C_{i}^{h}\left[\frac{I_{i}}{2}\left(t_{i}^{1}\right)+\frac{I_{i}+I_{i}^{\text {Max }}}{2}\left(t_{i}^{2}\right)+\frac{I_{i}^{\text {Max }}}{2}\left(t_{i}^{3}\right)\right.}^{\text {Holding Costof Items }}$

The joint production policy (Multi-Product Single-Machine) from Eq. (10) becomes:

$T C=\sum_{i=1}^{n} C_{i}^{P} D_{i}+\frac{\sum_{i=1}^{n} A_{i}}{T}+\sum_{i=1}^{n} C_{i}^{P} \beta_{i} D_{i}+\sum_{i=1}^{n} C_{i}^{h}\left[\frac{I_{i}}{2 T}\left(t_{i}^{1}\right)+\frac{I_{i}+I_{i}^{M a x}}{2 T}\left(t_{i}^{2}\right)+\frac{I_{i}^{\text {Max }}}{2 T}\left(t_{i}^{3}\right)\right.$.

\subsection{The constraint}

Since $t_{i}^{1}+t_{i}^{2}$ are the production and rework times and $S_{i}$ is the setup time for $i^{\text {th }}$ product, the summation of the production, rework and setup time (for all products) will be $\sum_{i=1}^{n}\left(t_{i}^{1}+t_{i}^{2}\right)+\sum_{i=1}^{n} S_{i}$, and it must be smaller or equal to the period length $(T)$. Therefore, the constraint of the model is:

$\sum_{i=1}^{n}\left(t_{i}^{1}+t_{i}^{2}\right)+\sum_{i=1}^{n} S_{i} \leq T$

Then, based on the Eq. (3), (4) and (9), we have:

$\sum_{i=1}^{n}\left(1+\beta_{i}\right) \frac{D_{i}}{P_{i}} T+\sum_{i=1}^{n} S_{i} \leq T$

\subsection{Final Model}

From Eq. (9), Eq. (11) and Eq. (13), TC in Eq. (11) and constraint in Eq. (13), one can formulate the optimization problem as:

$$
\begin{aligned}
\min : T C=\frac{\sum_{i=1}^{n} A_{i}}{T} & +\sum_{i=1}^{n} C_{i}^{h}\left[\left[\left(1-\beta_{i}\right) P_{i}-D_{i}\right] \frac{D_{i}}{2 P_{i}}+\beta_{i}\left[P_{i}-D_{i}\right] \frac{D_{i}}{P_{i}}\right]\left(1-\frac{D_{i}}{P_{i}}-\beta_{i} \frac{D_{i}}{P_{i}}\right) T^{2} \\
& +\sum_{i=1}^{n} C_{i}^{P} \beta_{i} D_{i}+\sum_{i=1}^{n} C_{i}^{h}\left(\left(1+\beta_{i}\right)\left[\left(1-\beta_{i}\right) P_{i}-D_{i}\right] \frac{D_{i}}{2 P_{i}}+\beta_{i}^{2}\left[P_{i}-D_{i}\right] \frac{D_{i}}{P_{i}^{2}}\right) T+\sum_{i=1}^{n} C_{i}^{P} D_{i}
\end{aligned}
$$




\section{Solution method}

$$
\text { subject to : } T \geq \frac{\sum_{i=1}^{n} S_{i}}{\left[1-\sum_{i=1}^{n}\left(1+\beta_{i}\right) \frac{D_{i}}{P_{i}}\right]}=T_{\text {Min }}
$$

In order to derive the optimal solution of the final model, a proof of the convexity of the objective function is provided. A classical optimization technique using partial derivatives is performed to derive the optimal solutions.

Theorem1. The objective function TC in Eq. (14) is convex.

Proof: To proof the convexity of $T C=Z$, the first and second derivatives of objective function are calculated as below:

$$
\begin{gathered}
\frac{\partial T C}{\partial T}=-\frac{\sum_{i=1}^{n} A_{i}}{T^{2}}+2 \sum_{i=1}^{n} C_{i}^{h}\left[\left[\left(1-\beta_{i}\right) P_{i}-D_{i}\right] \frac{D_{i}}{2 P_{i}}+\beta_{i}\left[P_{i}-D_{i}\right] \frac{D_{i}}{P_{i}}\right]\left(1-\frac{D_{i}}{P_{i}}-\beta_{i} \frac{D_{i}}{P_{i}}\right) T \\
+\sum_{i=1}^{n} C_{i}^{h}\left(\left(1+\beta_{i}\right)\left[\left(1-\beta_{i}\right) P_{i}-D_{i}\right] \frac{D_{i}}{2 P_{i}}+\beta_{i}^{2}\left[P_{i}-D_{i}\right] \frac{D_{i}}{P_{i}^{2}}\right) \\
\frac{\partial^{2} T C}{\partial T^{2}}=\frac{2 \sum_{i=1}^{n} A_{i}}{T^{3}}+2 \sum_{i=1}^{n} C_{i}^{h}\left[\left[\left(1-\beta_{i}\right) P_{i}-D_{i}\right] \frac{D_{i}}{2 P_{i}}+\beta_{i}\left[P_{i}-D_{i}\right] \frac{D_{i}}{P_{i}}\right]\left(1-\left(1+\beta_{i}\right) \frac{D_{i}}{P_{i}}\right) \geq 0
\end{gathered}
$$

Since the second derivative is non-negative so the objective function is convex and to obtain the optimal solution we have:

$a T^{3}+b T^{2}+c=0$

In which,

$$
\begin{aligned}
& a=2 \sum_{i=1}^{n} C_{i}^{h}\left[\left(\left(1-\beta_{i}\right) P_{i}-D_{i}\right) \frac{D_{i}}{2 P_{i}}+\beta_{i}\left(P_{i}-D_{i}\right) \frac{D_{i}}{P_{i}}\right]\left(1-\frac{D_{i}}{P_{i}}-\beta_{i} \frac{D_{i}}{P_{i}}\right) \geq 0 \\
& b=\sum_{i=1}^{n} C_{i}^{h}\left(\left(1+\beta_{i}\right)\left(\left(1-\beta_{i}\right) P_{i}-D_{i}\right) \frac{D_{i}}{2 P_{i}}+\beta_{i}^{2}\left(P_{i}-D_{i}\right) \frac{D_{i}}{P_{i}^{2}}\right) \geq 0 \\
& c=-\sum_{i=1}^{n} A_{i} \leq 0
\end{aligned}
$$

The solution of Eq. (18) is being obtained numerically by any numeric method such as NewtonRaphson. To solve and ensure the feasibility, the following solution procedure must be performed:

Solution procedure:

Step1. Check for feasibility, If $\sum_{i=1}^{n}\left(1+\beta_{i}\right) \frac{D_{i}}{P_{i}} \leq 1$ and $\left[\left(1-\beta_{i}\right) P_{i}-D_{i}\right] \geq 0$, go to step 2, else the problem will be infeasible,

Step2. Calculate $T$ using numeric method. If $T \geq 0$, go to step 3, else the problem will be infeasible,

Step3. Calculate by $T_{\text {Min }}$ Eq. (15),

Step4. If $T \geq T_{\text {Min }}$ then $T^{*}=T$ else $T^{*}=T_{\text {Min }}$,

Step5. Calculate $Q_{i}^{*}$ by Equation (9),

Step6. Terminate procedure. 


\section{Numerical examples and sensitivity analysis}

\subsection{Numerical Example}

Consider two multi-products EPQ problems with breakdown and immediate rework with five products in which their general and specific data are given in Table 1 and Table 2, respectively. Tables 3 and Table 4 show the best results for the two numerical examples. For the first example, since the value of $T$ is greater than $T_{\text {Min }}$ the $4^{\text {th }}$ step of the procedure implies the optimality of $T$. However, in the second example we chose $T_{\text {Min }}$ as the optimal solution since $T$ is less than $T_{M i n}$.

\section{Table 1}

General data for the first example

\begin{tabular}{llllllll}
\hline Product & $D_{i}$ & $P_{i}$ & $S_{i}$ & $A_{i}$ & $C_{i}^{P}$ & $C_{i}^{h}$ & $\beta_{i}$ \\
\hline 1 & 400 & 3500 & 0.003 & 500 & 15 & 5 & 0.1 \\
\hline 2 & 500 & 4000 & 0.004 & 450 & 12 & 4 & 0.2 \\
\hline 3 & 600 & 4500 & 0.005 & 400 & 10 & 3 & 0.3 \\
\hline 4 & 700 & 5000 & 0.006 & 350 & 8 & 2 & 0.4 \\
\hline 5 & 800 & 5500 & 0.007 & 300 & 6 & 1 & 0.5 \\
\hline
\end{tabular}

Table 2

General data for the second example

\begin{tabular}{llllllll}
\hline Product & $D_{i}$ & $P_{i}$ & $S_{i}$ & $A_{i}$ & $C_{i}^{P}$ & $C_{i}^{h}$ & $\beta_{i}$ \\
\hline 1 & 400 & 3000 & 0.003 & 500 & 15 & 5 & 0.1 \\
\hline 2 & 500 & 3500 & 0.004 & 450 & 12 & 4 & 0.2 \\
\hline 3 & 600 & 4000 & 0.005 & 400 & 10 & 3 & 0.3 \\
\hline 4 & 700 & 4500 & 0.006 & 350 & 8 & 2 & 0.4 \\
\hline 5 & 800 & 5000 & 0.007 & 300 & 6 & 1 & 0.5 \\
\hline
\end{tabular}

\section{Table 3}

The best results for the first example

\begin{tabular}{|c|c|c|c|c|c|}
\hline \multirow{2}{*}{ Product } & \multicolumn{5}{|l|}{ Uniform } \\
\hline & $T_{\text {Min }}$ & $T$ & $T^{*}$ & $Q_{i}$ & $Z$ \\
\hline 1 & \multirow{5}{*}{0.1827879} & \multirow{5}{*}{0.5408731} & \multirow{5}{*}{0.5408731} & 216.3492 & \multirow{5}{*}{42998.16} \\
\hline 2 & & & & 270.4366 & \\
\hline 3 & & & & 324.5239 & \\
\hline 4 & & & & 378.6112 & \\
\hline 5 & & & & 432.6985 & \\
\hline
\end{tabular}

Table 4

The best results for the second example

\begin{tabular}{|c|c|c|c|c|c|}
\hline \multirow{2}{*}{ Product } & \multicolumn{5}{|l|}{ Uniform } \\
\hline & $T_{M i n}$ & $T$ & $T^{*}$ & $Q_{i}$ & $Z$ \\
\hline 1 & \multirow{5}{*}{0.8583106} & \multirow{5}{*}{0.5496333} & \multirow{5}{*}{0.8583106} & 343.3243 & \multirow{5}{*}{43955.41} \\
\hline 2 & & & & 429.1553 & \\
\hline 3 & & & & 514.9864 & \\
\hline 4 & & & & 600.8174 & \\
\hline 5 & & & & 686.6485 & \\
\hline
\end{tabular}




\subsection{Sensitivity Analysis}

To study the effects of the parameter changes on the optimal solutions derived by the proposed method, this investigation performs a sensitivity analysis by increasing or decreasing the parameters, one at a time, by $20 \%$ and $50 \%$. Section 4.1 gives two numerical examples, and section 4.2 gives the sensitivity analyses. Tables 5 and 6 show the results of the sensitivity analysis for examples 1 and 2, respectively.

\section{Table 5}

Effects of Parameter Changes for the First Example

\begin{tabular}{|c|c|c|c|c|c|}
\hline \multirow{2}{*}{\multicolumn{2}{|c|}{$\begin{array}{l}\text { \% Changes } \\
\text { in parameters and their values }\end{array}$}} & \multicolumn{4}{|c|}{ \% Changes in } \\
\hline & & \multirow{2}{*}{$\frac{T_{M i n}}{-67.78}$} & \multirow{2}{*}{$\frac{T}{-6.33}$} & \multirow{2}{*}{$\frac{T^{*}}{-6.33}$} & \multirow{2}{*}{$\frac{Z}{+0.86}$} \\
\hline \multirow{4}{*}{$P_{i}$} & +50 & & & & \\
\hline & +20 & -51.27 & -3.27 & -3.27 & +0.43 \\
\hline & -20 & Infeasible & - & - & - \\
\hline & -50 & Infeasible & - & - & - \\
\hline \multirow{4}{*}{$A_{i}$} & +50 & 0 & +31.18 & +31.18 & +3.35 \\
\hline & +20 & 0 & +13.15 & +13.15 & +1.39 \\
\hline & -20 & 0 & -14.36 & -14.36 & -1.47 \\
\hline & -50 & 0 & -39.07 & -39.07 & -3.91 \\
\hline \multirow{4}{*}{$D_{i}$} & +50 & Infeasible & - & - & - \\
\hline & +20 & Infeasible & - & - & - \\
\hline & -20 & -55.08 & +11.76 & +11.76 & -18.18 \\
\hline & -50 & -75.94 & +43.56 & +43.96 & -46 \\
\hline \multirow{4}{*}{$\beta_{i}$} & +50 & +299.98 & +4.18 & +103.04 & +8.25 \\
\hline & +20 & +42.85 & +1.37 & +1.37 & +3.54 \\
\hline & -20 & -23.08 & -1.02 & -1.02 & -3.59 \\
\hline & -50 & -42.86 & -1.87 & -1.87 & -9.07 \\
\hline \multirow{4}{*}{$S_{j}$} & +50 & +50 & 0 & 0 & 0 \\
\hline & +20 & +20 & 0 & 0 & 0 \\
\hline & -20 & -20 & 0 & 0 & 0 \\
\hline & -50 & -50 & 0 & 0 & 0 \\
\hline
\end{tabular}

As we have already explained, $T^{*}$ can be found either directly using numeric method proposed in earlier or it can be obtained from the lower bound. However, in the case of example, some change on $P_{i}$ forces the optimality to be calculated by the lower bound and we experience significant changes on $T^{*}$. We have similar experience between $D_{i}$ and $T^{*}$. In fact $T^{*}$ is very sensitive to the changes of parameters $D_{i}$ and $P_{i}$. In examples (1) and (2) when $P_{i}$ is decreased or $D_{i}$ is increased, the problems become infeasible (See Table 5 and Table 6). The other observation is that when we assign different values for $D_{i}$ and $P_{i}, T_{\text {Min }}$ becomes negative which means feasible solutions. In the first example $T^{*}$ is obtained from numeric method, which means that satisfies the lower bound (capacity limitation). However, when $\beta_{i}$ is increased by +50 percents, the value of numeric method is changed and it does not satisfy the lower bound which means that $T_{\text {Min }}$ needs to be considered as the optimal values of $T$ and the changes values of $T^{*}$ are greater than 100 percents. The following summarizes our experimental results.

- $T_{M i n}$ is highly sensitive to the changes in the values of parameters $P_{i}, D_{i}, \beta_{i}$ and $S_{i}$. Also $T_{M i n}$ is also insensitive to the changes in the values of parameter $A_{i}$.

- $\quad T$ is slightly sensitive to the changes in the values of $P_{i}$ and $\beta_{i}$, highly sensitive to the changes in the values of parameters $D_{i}$ and $A_{i}$. Also $T$ is insensitive to the changes in the values of parameter $S_{i}$. 
- $Z$ is slightly sensitive to the changes in the values of parameters $P_{i}, A_{i}, \beta_{i}$ and $S_{i}$ and it is highly sensitive to the changes in the values of parameter $D_{i}$.

Table 6

Effects of parameter changes for the second example

\begin{tabular}{|c|c|c|c|c|c|}
\hline \multirow{2}{*}{\multicolumn{2}{|c|}{$\begin{array}{l}\text { \% Changes } \\
\text { in parameters and their values }\end{array}$}} & \multicolumn{4}{|c|}{ \% Changes in } \\
\hline & & \multirow{2}{*}{$\frac{T_{\text {Min }}}{-91.74}$} & \multirow{2}{*}{$\frac{T}{-7.26}$} & \multirow{2}{*}{$\frac{T^{*}}{-60.04}$} & \multirow{2}{*}{$\begin{array}{ll}Z \\
+0.13 \\
\end{array}$} \\
\hline \multirow{4}{*}{$P_{i}$} & +50 & & & & \\
\hline & +20 & -84.75 & -3.76 & -58.54 & -0.35 \\
\hline & -20 & Infeasible & - & - & - \\
\hline & -50 & Infeasible & - & - & - \\
\hline \multirow{4}{*}{$A_{i}$} & +50 & 0 & +31.16 & 0 & +2.65 \\
\hline & +20 & 0 & +13.15 & 0 & +1.06 \\
\hline & -20 & 0 & -14.33 & 0 & -1.06 \\
\hline & -50 & 0 & -39.03 & 0 & -2.67 \\
\hline \multirow{4}{*}{$D_{i}$} & +50 & Infeasible & - & - & - \\
\hline & +20 & Infeasible & - & - & - \\
\hline & -20 & -86.96 & +11.08 & -52.14 & -18.82 \\
\hline & -50 & -94.34 & +41.47 & -39.05 & -46.37 \\
\hline \multirow{4}{*}{$\beta_{i}$} & +50 & Infeasible & - & - & - \\
\hline & +20 & Infeasible & - & - & - \\
\hline & -20 & -61.14 & -1.16 & -57.42 & -4.39 \\
\hline & -50 & -79.73 & -2.23 & -57.87 & $\begin{array}{l}-9.82 \\
\end{array}$ \\
\hline \multirow{4}{*}{$S_{j}$} & +50 & +50 & 0 & +50 & +8.14 \\
\hline & +20 & +20 & 0 & +20 & +2.74 \\
\hline & -20 & -20 & 0 & -20 & -1.85 \\
\hline & -50 & -50 & 0 & -50 & -1.78 \\
\hline
\end{tabular}

\section{Conclusions and future researches}

This study developed an EPQ model with production capacity limitation and breakdown with immediate rework. The primary aim of this research has been to determine the optimal period lengths and lot sizes for each product. The objective function of the proposed mathematical model has been proved to be convex. Two numerical examples are used to illustrate the implementation of our proposed method and sensitivity analysis has been performed to show the applicability of the proposed methodology. The study provided managerial insights for practitioners in designing an EPQ inventory model with breakdown and immediate rework. Future research could focus on backordered or partial backordering strategies and multi-product multi-constraint problems in an uncertain environment and also explore the problem when the lot sizes are restricted to be integers.

\section{References}

Bayindir, Z.P., Birbil, S.I., \& Frenk, J.B.G. (2007). A deterministic inventory/production model with general inventory cost rate function and piecewise linear concave production costs. European Journal of Operational Research, 179, 114-123.

Cárdenas-Barrón, L.E., (2007). On optimal manufacturing batch size with rework process at single-stage production system. Computers and Industrial Engineering, 53, 196-198.

Cárdenas-Barrón, L.E., (2008). Optimal manufacturing batch size with rework in a single-stage production system - A simple derivation, Computers and Industrial Engineering, 55, 758-765.

Cárdenas-Barrón, L.E., (2009a). On optimal batch sizing in a multi-stage production system with rework consideration. European Journal of Operational Research, 196, 1238-1244.

Cárdenas-Barrón, L.E., (2009b). Economic production quantity with rework process at a single-stage manufacturing system with planned backorders, Computers and Industrial Engineering, 57, 1105-1113.

Chan, W.M., Ibrahim, R.N., \& Lochert, P.B. (2003). A new EPQ model: integrating lower pricing, rework and reject situations. Production Planning \& Control, 14, 588 - 595. 
Cheng, T.C.E. (1991). An economic order quantity model with demand-dependent unit production cost and imperfect production processes. IIE Transactions, 23, 23-28.

Chiu, S.W., Chiu, Y.P., \& Wu, B.P. (2003). An economic production quantity model with the steady production rate of scrap items. The Journal of Chaoyang University of Technology, 8, 225-235.

Chiu, S.W., \& Chiu, Y.P. (2003). Mathematical modeling for production system with backlogging and failure in repair. Journal of Scientific and Industrial Research, 65,499-506.

Chiu, Y.P. (2003). Determining the optimal lot size for the finite production model with random defective rate, the rework process, and backlogging. Engineering Optimization, 35,427-437.

Chiu, S.W., Gong, D.C., \& Wee, H.M. (2004). Effects of random defective rate and imperfect rework process on economic production quantity model. Japan Journal of Industrial and Applied Mathematics, 21, 375389.

Chiu, S.W. (2007). Optimal replenishment policy for imperfect quality EMQ model with rework and backlogging. Applied Stochastic Models in Business and Industry, 23,165-178.

Chiu, S.W., Wang, S.L., \& Chiu, Y.S.P. (2007). Determining the optimal run time for EPQ model with scrap, rework, and stochastic breakdowns. European Journal of Operational Research, 180,664-676.

Chiu, S.W. (2008). Production lot size problem with failure in repair and backlogging derived without derivatives. European Journal of Operational Research, 188,610-615.

Chung, K.J. (1997). Bounds for production lot sizing with machine breakdown. Computer \& Industrial Engineering, 32,139-144.

Hayek, P.A., \& Salameh, M.K. (2001). Production lot sizing with the reworking of imperfect quality items produced. Production Planning \& Control, 12,584-590.

Hou, K.L. (2007). An EPQ model with setup cost and process quality as functions of capital expenditure. Applied Mathematical Modeling, 31, 10-17.

Islam, S., \& Roy, T.K. (2006). A fuzzy EPQ model with flexibility and reliability consideration and demand dependent unit production cost under a space constraint: A fuzzy geometric programming approach. Applied Mathematics and Computations, 176,531-544.

Jamal, A.M.M., Sarker, B.R., \& Mondal, S. (2004). Optimal manufacturing batch size with rework process at a single-stage production system. Computer \& Industrial Engineering, 47, 77-89.

Lee, H.L., \& Rosenblatt, M. (1987). Simultaneous determination of production cycle and inspection schedules in a production system. Management Science, 33, 1125-1136.

Li, J., Wang, S., \& Cheng, T.C.E. (2008) Analysis of postponement strategy by EPQ-based models with planned backorders. Omega, 36,777-788.

Pentico, W.D., Drake, M.J., Toews, C. (2009). The deterministic EPQ with partial back ordering: A new approach. Omega, 37,624-636.

Rosenblatt, M.J., \& Lee, H.L. (1986) Economic production cycles with imperfect production processes. IIE Transactions, 18, 48-55.

Sarker, B.R.J., Jamal, A.M.M., \& Mondal, S. (2008). Optimal batch sizing in a process at multi-stage production system with network consideration, European Journal of Operational research, 184, 915-929.

Taleizadeh, A.A., Najafi, A.A., \& Niaki, S.T.A. (2010a). Economic production quantity model with scraped items and limited production capacity. International Journal of Science and Technology (Scientia Iranica), 17, 58-69.

Taleizadeh, A.A., Niaki, S.T.A., \& Najafi, A.A. (2010b). Multiproduct single-machine production system with stochastic scrapped production rate, partial backordering and service level constraint. Journal of Computational and Applied Mathematics, 233, 1834-1849.

Taleizadeh, A.A., Wee, H.M., \& Sadjadi S.J. (2010c). Multi-Product Production Quantity Model With Repair Failure and Partial Back-ordering, Computers and Industrial Engineering, 59:45-54.

Taleizadeh, A.A., Widyadana, G.A., Wee, H.M., \& Biabani, J. (2011a). Multi products single machine economic production quantity model with multiple batch size. International Journal of Industrial Engineering Computations, 2, 213-224.

Taleizadeh, A.A., Sadjadi S.J., \& Niaki S.T.A. (2011b). Multi-Product Single-Machine EPQ Model with Immediate Rework Process and Back-Ordering, European Journal of Industrial Engineering, In Press.

Teng J.T., \& Chang, C.T. (2009). Optimal manufacturer's replenishment policies in the EPQ model under two levels of trade credit policy. European Journal of Operational Research, 195:358-363.

Wee, H.M., Jonas, Y.u., \& Chen, M.C. (2007). Optimal inventory model for items with imperfect quality and shortage backordering. Omega, 35, 7-11. 